\title{
Vaccine safety surveillance in Canada: Reports to CAEFISS, 2017
}

\author{
K Johnson ${ }^{1 *}, \mathrm{H}^{\text {Anyoti }}{ }^{1}, \mathrm{C}$ Coulby ${ }^{1}$
}

\section{Abstract}

Background: Canada has a comprehensive vaccine safety surveillance system that includes both passive and active surveillance of vaccines administered in Canada.

Objectives: To provide 1) a descriptive analysis of the adverse events following immunization (AEFI) reports for vaccines administered in Canada, 2) a descriptive review of health care utilization and outcome following an AEFI and 3) an analysis of serious adverse events (SAEs).

Methods: Data was obtained from the Canadian Adverse Events Following Immunization Surveillance System (CAEFISS), which includes both passive and active surveillance. Descriptive analyses were conducted of AEFI reports arising from vaccines administered from January 1, 2017 to December 31, 2017 and received by April 30, 2018. Data elements included AEFIs, demographics, health care utilization, outcome, and seriousness of adverse events.

Results: There were 2,960 AEFI reports submitted to CAEFISS from across Canada for vaccines administered in 2017. The AEFI reporting rate was $12.6 / 100,000$ doses distributed $(8.1 / 100,000$ population) in Canada for vaccines administered in 2017 and was found to be inversely proportional to age. The majority of reports $(91 \%)$ were non-serious events, primarily involving vaccination site reactions such as rash, and allergic events. Overall, there were 253 SAE reports, for a reporting rate of 1.1/100,000 doses distributed in 2017. Of the SAE reports, the most common primary AEFls were seizure $(n=58,23 \%)$ followed by anaphylaxis $(n=33,13 \%)$. There were no unexpected vaccine safety issues identified or increases in frequency or severity of expected adverse events.

Conclusion: Canada's continuous monitoring of the safety of marketed vaccines in 2017 did not identify any increase in the frequency or severity of AEFIs, previously unknown AEFIs or areas that required further investigation or research. Vaccines marketed in Canada continue to have an excellent safety profile.

Suggested citation: Johnson K, Anyoti H, Coulby C. Vaccine safety surveillance in Canada: Reports to CAEFISS, 2017. Can Commun Dis Rep 2018;44(12): 333-39. https://doi.org/10.14745/ccdr.v44i12a04

\author{
Affiliation \\ ${ }^{1}$ Canadian Adverse Events \\ Following Immunization \\ Surveillance System (CAEFISS), \\ Centre for Immunization and \\ Respiratory Infectious Diseases, \\ Public Health Agency of Canada, \\ Ottawa, ON \\ *Correspondence: \\ phac.aefi-essi.aspc@canada.ca
}

Keywords: vaccine safety, adverse events, immunization, surveillance, CAEFISS

\section{Introduction}

Post-market vaccine safety surveillance is essential to detect any emerging vaccine safety issues and to maintain public confidence in vaccines. The Public Health Agency of Canada (PHAC) works together with Health Canada, the regulator, to ensure a comprehensive post-market vaccine safety surveillance system.
The Canadian Adverse Events Following Immunization Surveillance System (CAEFISS) is a federal, provincial and territorial (FPT) public health post-market vaccine safety surveillance system. CAEFISS is managed by PHAC and is unique in that it includes both passive (spontaneous reports from FPTs) and active surveillance. Active surveillance is conducted by Immunization Monitoring Program ACTive (IMPACT); a network 
of 12 pediatric hospitals across Canada that screens hospital admissions for specific adverse events following immunizations (AEFIs). The primary objectives of CAEFISS are to:

- Continuously monitor the safety of marketed vaccines in Canada

- Identify increases in the frequency or severity of previously identified vaccine-related reactions

- Identify previously unknown AEFls that could possibly be related to a vaccine

- Identify areas that require further investigation and/or research and

- $\quad$ Provide timely information on AEFI reporting profiles for vaccines marketed in Canada, which could help inform immunization programs and guidelines (1)

In Canada, health care providers, manufacturers and the public each have a role to play in vaccine pharmacovigilance (2). The FPT public health officials monitor vaccine safety through the Vaccine Vigilance Working Group (VWWG) of the Canadian Immunization Committee (CIC). The WWW includes representatives from all FPT immunization programs across the country as well as Health Canada regulators and IMPACT. This report was developed with input and support from the VWWG.

National reports on vaccine safety surveillance data have been published periodically $(3,4)$. The objective of this report is to provide a) a descriptive analysis of AEFI reports for vaccines administered in Canada in 2017, b) a descriptive review of health care utilization and outcome following an AEFI and c) an analysis of serious adverse events (SAEs).

\section{Methods}

\section{Definitions}

An AEFI is defined as any untoward medical occurrence that follows immunization but that does not necessarily have a causal relationship with the administration of the vaccine. The adverse event may be a sign, symptom or defined illness (5).

A SAE in CAEFISS is identified based on the International Conference on Harmonization of Technical Requirements for Registration of Pharmaceuticals for Human Use as an event that results in death, is life-threatening, requires in-patient hospitalization or prolongation of existing hospitalization, results in persistent or significant disability/incapacity or results in a congenital anomaly/birth defect. Any medical event which may not be immediately life-threatening but requires intervention to prevent one of the outcomes listed above may also be considered as serious (6).

\section{Data sources}

The CAEFISS is an FPT collaborative process that includes submission of AEFI reports from both passive and active surveillance. Passive surveillance is initiated at the local public health level. Completed reports are first sent to provincial and territorial (PT) health authorities and are then submitted on a voluntary basis to PHAC for inclusion into CAEFISS (7). In addition, CAEFISS also receives reports from federal authorities (Indigenous Services Canada, Correctional Services Canada, Royal Canadian Mounted Police, National Defence and the Canadian Armed Forces). These reports are entered into CAEFISS and a copy and/or reporter information is sent to the health authorities of the jurisdiction of origin.

Active surveillance is conducted by IMPACT nurse monitors, under the supervision of pediatric and/or infectious disease medical specialists, who screen hospital admissions for target AEFls that may have followed vaccination and that led to a hospital admission $(8,9)$.

All AEFI reports are entered into CAEFISS and serious AEFIs are identified and coded using the International Medical Dictionary for Regulatory Activities (MedDRA version 17, McLean, Virginia, United States [US]) (10). A systematic medical case review is conducted by trained health professionals who assign a primary reason for reporting using national case definitions for $\mathrm{AEFI}$ classification from the CAEFISS user guide (11). For more detailed information on CAEFISS and report processing and quality assurance, please refer to previous published reports $(3,4)$.

Reporting rates are calculated with two different denominators. When possible, vaccine doses distributed data, which is provided by Market Authorization Holders, is used to calculate the doses distributed-based rate. This is not adjusted for doses returned or wastage. When the doses distributed data is not available, annual population estimates from Statistics Canada are used to calculate a population-based rate (12).

\section{Data analysis}

All AEFI reports submitted to CAEFISS by April 30, 2018 with a date of vaccine administration from January 1, 2017 through December 31, 2017 were included in this report. In addition, all AEFI reports following vaccines administered from 2007 onwards were included to assess trends over time. Data were extracted from CAEFISS on May 27, 2018. Of note, reports submitted to CAEFISS for 2017 are known to be incomplete due to data entry delays in one region of one jurisdiction (which accounts for less than $2 \%$ of the total reports submitted to CAEFISS in 2017).

Descriptive analyses are conducted using SAS Enterprise Guide software, Version 5.1 (Cary, North Carolina, US) (13). Calculations were presented for all vaccines combined to calculate the overall rate by doses distributed for the year 2017 as well as rates by year (2007-2017), type of surveillance, primary reason for reporting, primary AEFI by seriousness and health care utilization and outcome for vaccines administered in 2017. Sex- and age-specific rates were calculated using population estimates as the denominator. Missing data were excluded from the calculations. 


\section{SURVEILLANCE}

\section{Results}

The CAEFISS received a total of 2,960 AEFI reports from 13 provinces and territories for vaccines administered in 2017. Over 23 million vaccine doses (public and private) were distributed, representing a reporting rate of 12.6 per 100,000 doses distributed. Over the last 11 years, the $A E F I$ reporting rate decreased $(p<0.01)$ with reporting rates ranging from 12.6 to 21.9 per 100,000 doses distributed (Figure 1). While only $7 \%$ $(n=116)$ of all submitted AEFI reports in children less than 18 years of age were through active surveillance, they represented $56 \%(n=116)$ of all SAE reports submitted for this age group (Note: Data not shown; numbers do not completely correspond to the percentages as the percentages have been rounded to the nearest integer). This distribution is consistent with previous years (4).

Figure 1: Total number of adverse events following immunization reports and reporting rate by reporting source and year, 2007-2017

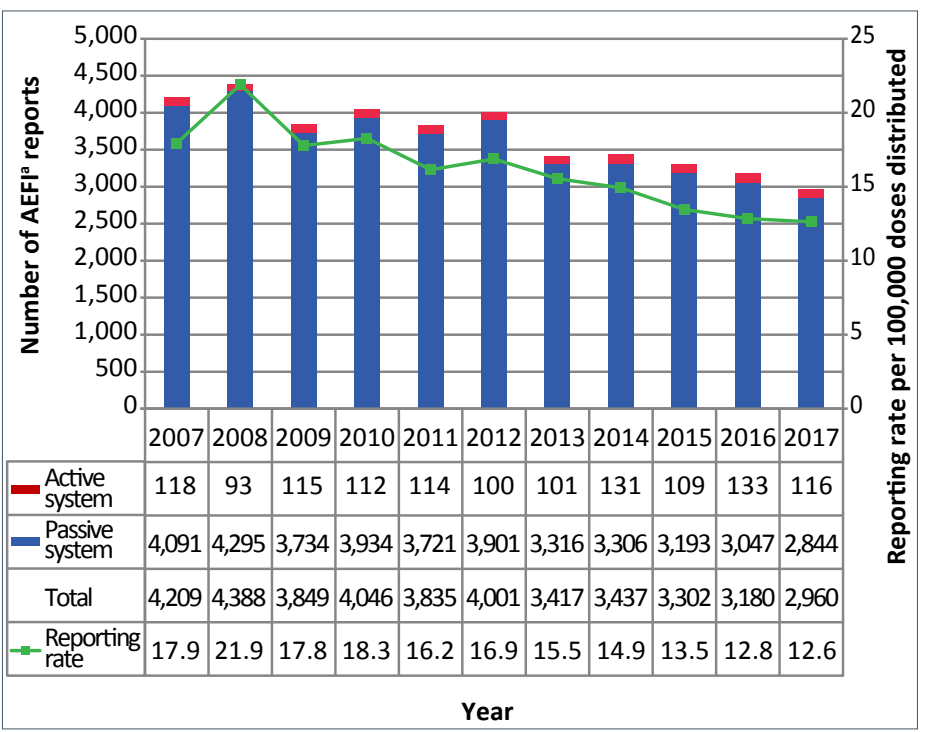

Abbreviation: $\mathrm{AEFI}$, adverse event following immunization

a Does not include the H1N1-09 pandemic influenza AEFI reports

\section{Age and sex distribution}

The number of reports and the reporting rates per 100,000 population by age group and sex are presented in Figure 2. The median age of all reports during the reporting period was 10 years (range: one day to 97 years). The majority (60\%) of AEFI reports were for children and adolescents under 18 years of age. The highest reporting rates were seen in children one to less than two years of age (136.5/100,000 population), followed by infants less than one year of age (119.6/100,000 population).

Decreases in the reporting rate were seen in all age groups less than seven years of age $(p<0.01)$ between 2007 and 2017, with the greatest decreases seen in the one to less than two year age group (302.5 versus $136.5 / 100,000$ population respectively)
Figure 2: Number and reporting rate of adverse events following immunization reports by age group and sex, $2017^{\mathrm{a}}$

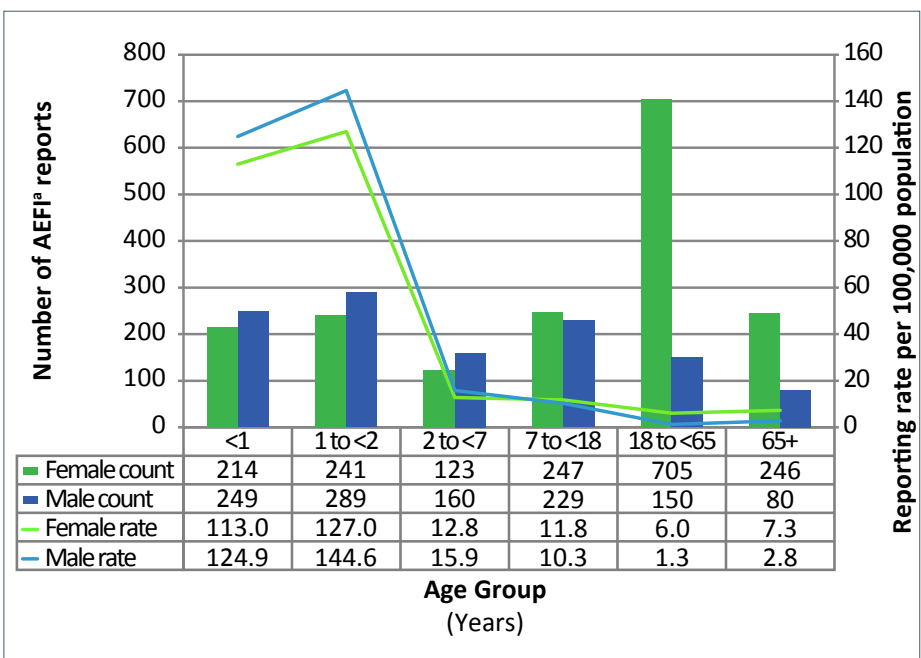

Abbreviations: AEFI, adverse event following immunization; <, less than; + , and above a Eighteen reports with missing age, nine reports with missing sex and one report indicating sex as "other" were excluded

and the less than one year age group (182.8 vs $119.6 / 100,000$ population respectively) (data not shown).

Of the 2,960 reports, $60 \%$ of reports were in females. As shown in Figure 2, male predominance was observed for children under seven years of age and female predominance was observed among those seven years of age and older. Two age groups had a significant difference between female and male reporting rates: the 18 to 64 year age group had a rate ratio (RR) of $4.6(95 \%$ confidence interval $[\mathrm{Cl}] 3.86$ to $5.49 ; p<0.05)$ and the 65 and older age group had a RR of $2.6(95 \% \mathrm{Cl} 2.02$ to $3.35 ; p<0.05)$, indicating that submitted AEFI reports were over four and a half times and two and half times more likely to be in females, respectively.

\section{Primary reason for reporting}

During the medical case review process, a primary AEFI category is assigned as the main reason for reporting and is further classified to a sub-category. Excluding the 'other' category, the most common primary AEFls reported for vaccines administered in 2017 were vaccination site reactions $(n=1,339,45 \%)$ followed by allergic reaction $(n=417,14 \%)$ and rash alone $(n=346,12 \%)$ (Table 1).

The proportion of serious events was highest for the neurological event category (44\%), followed by infection/syndrome/systemic symptoms (ISS) (22\%). Of note, vaccination errors included only a small number of reports (fewer than five AEFI reports) and no serious reports.

Figure 3 shows the distribution of AEFls by primary reason by age group. Vaccination site reactions represented the greatest number of AEFls for all the age groups except for children less than one year of age. Excluding the "other" event category for 
Table 1: Frequency of reports and percent that is serious for each primary adverse event following immunization sub-category, 2017

\begin{tabular}{|c|c|c|c|}
\hline $\begin{array}{l}\text { Primary AEFI } \\
\text { category }\end{array}$ & $\begin{array}{l}\text { Primary AEFI } \\
\text { sub-category }\end{array}$ & $\begin{array}{l}\text { Number of } \\
\text { reports } \\
(\mathrm{N}=2,957)^{\mathrm{a}}\end{array}$ & $\begin{array}{l}\text { Serious } \\
\text { event } \\
\text { (\%) }\end{array}$ \\
\hline \multirow{5}{*}{$\begin{array}{l}\text { Allergic or } \\
\text { allergic-like events }\end{array}$} & Anaphylaxis & 33 & 100 \\
\hline & Other allergic events ${ }^{b}$ & 355 & 1 \\
\hline & $\begin{array}{l}\text { Oculo-respiratory } \\
\text { syndrome (ORS) }\end{array}$ & 28 & 0 \\
\hline & Rash & 1 & 0 \\
\hline & TOTAL & 417 & 9 \\
\hline \multirow{7}{*}{$\begin{array}{l}\text { Infection/ } \\
\text { syndrome/ } \\
\text { systemic } \\
\text { symptoms (ISS) }\end{array}$} & Fever only & 11 & 27 \\
\hline & Infection & 28 & 36 \\
\hline & Influenza-like illness (ILI) & 10 & 0 \\
\hline & $\begin{array}{l}\text { Rash with fever and/or } \\
\text { other illness }\end{array}$ & 61 & 10 \\
\hline & $\begin{array}{l}\text { Syndromes (e.g., } \\
\text { Kawasaki) }\end{array}$ & 16 & 88 \\
\hline & $\begin{array}{l}\text { Systemic (when several } \\
\text { body systems are } \\
\text { involved) }\end{array}$ & 55 & 11 \\
\hline & TOTAL & 181 & 22 \\
\hline \multirow[t]{9}{*}{ Neurologic events } & Aseptic meningitis & 3 & 67 \\
\hline & Ataxia/cerebellitis ${ }^{c}$ & 2 & 50 \\
\hline & Bell's palsy & 6 & 17 \\
\hline & $\begin{array}{l}\text { Encephalitis / } \\
\text { acute disseminated } \\
\text { encephalomyelitis } \\
\text { (ADEM) / myelitis }\end{array}$ & 5 & 100 \\
\hline & $\begin{array}{l}\text { Guillain-Barré syndrome } \\
\text { (GBS) }\end{array}$ & 2 & 50 \\
\hline & $\begin{array}{l}\text { Other paralysis lasting } \\
\text { more than one day }\end{array}$ & 1 & 100 \\
\hline & Seizure & 111 & 52 \\
\hline & Other neurologic event ${ }^{d}$ & 47 & 17 \\
\hline & TOTAL & 177 & 44 \\
\hline \multirow[t]{4}{*}{ Rash alone } & Generalized & 291 & 0 \\
\hline & Localized & 35 & 0 \\
\hline & $\begin{array}{l}\text { Location not specified/ } \\
\text { extent unknown }\end{array}$ & 20 & 0 \\
\hline & TOTAL & 346 & 0 \\
\hline \multirow{4}{*}{$\begin{array}{l}\text { Immunization } \\
\text { anxiety }\end{array}$} & Presyncope & 6 & 0 \\
\hline & Syncope & 33 & 6 \\
\hline & $\begin{array}{l}\text { Other anxiety-related } \\
\text { event }{ }^{\mathrm{e}}\end{array}$ & 7 & 0 \\
\hline & TOTAL & 46 & 4 \\
\hline \multirow[t]{7}{*}{$\begin{array}{l}\text { Vaccination site } \\
\text { reactions }\end{array}$} & $\begin{array}{l}\text { Abscess (infected or } \\
\text { sterile) }\end{array}$ & 13 & 31 \\
\hline & Cellulitis & 329 & 5 \\
\hline & $\begin{array}{l}\text { Extensive limb swelling } \\
(E L S)^{f}\end{array}$ & 136 & 2 \\
\hline & $\begin{array}{l}\text { Pain in the vaccinated } \\
\text { limb of seven days or } \\
\text { more }\end{array}$ & 56 & 0 \\
\hline & Other local reactiong ${ }^{9}$ & 804 & 2 \\
\hline & Rash & 1 & 0 \\
\hline & TOTAL & 1,339 & 3 \\
\hline Vaccination error & $\begin{array}{l}\text { Vaccination error } \\
\text { TOTAL }\end{array}$ & 3 & 0 \\
\hline \multirow[t]{5}{*}{ Other } & Arthralgia & 16 & 0 \\
\hline & Arthritis & 5 & 20 \\
\hline & Gastrointestinal event & 169 & 5 \\
\hline & $\begin{array}{l}\text { Hypotonic- } \\
\text { hyporesponsive } \\
\text { episode (HHE) }\end{array}$ & 17 & 24 \\
\hline & Intussusception & 6 & 83 \\
\hline
\end{tabular}

Table 1: (continued) Frequency of reports and percent that is serious for each primary adverse event following immunization sub-category, 2017

\begin{tabular}{|l|l|r|r|}
\hline $\begin{array}{c}\text { Primary AEFI } \\
\text { category }\end{array}$ & \multicolumn{1}{|c|}{$\begin{array}{c}\text { Primary AEFI } \\
\text { sub-category }\end{array}$} & $\begin{array}{c}\text { Number of } \\
\text { reports } \\
(\mathrm{N}=2,957)^{\mathrm{a}}\end{array}$ & $\begin{array}{c}\text { Serious } \\
\text { event } \\
(\%)\end{array}$ \\
\hline Other (continued) & $\begin{array}{l}\text { Anaesthesia/ } \\
\text { paraesthesia }\end{array}$ & 9 & 5 \\
\cline { 2 - 4 } & Parotitis & 16 & 6 \\
\cline { 2 - 4 } & Persistent crying & 0 & $\mathrm{~N} / \mathrm{A}$ \\
\cline { 2 - 4 } & $\begin{array}{l}\text { Sudden infant death } \\
\text { syndrome (SIDS) }\end{array}$ & 0 & $\mathrm{~N} / \mathrm{A}$ \\
\cline { 2 - 4 } & $\begin{array}{l}\text { Sudden unexpected/ } \\
\text { unexplained death } \\
\text { syndrome (SUDS) }\end{array}$ & 25 & 80 \\
\cline { 2 - 4 } & Thrombocytopenia & 163 & 12 \\
\cline { 2 - 4 } & Other events & & 13 \\
\cline { 2 - 4 } & TOTAL & 448 & \\
\hline
\end{tabular}

Abbreviations: AEFI, adverse events following immunization; N/A, not applicable; $N$, total number a Three reports with missing primary AEFI sub category are excluded

"Other" includes, but is not limited to, hypersensitivity and urticarial

Cerebellar ataxia is defined as sudden onset of truncal ataxia and gait disturbances (14). Of note, this assumed absence of cerebellar signs appearing with other evidence of encephalitis or acute disseminated encephalomyelitis (ADEM), in which case it would be classified according to the Brighton-Collaboration case definition (15)

$d$ "Other" includes, but is not limited to, seizure-like phenomena and migraine

"Other" includes, but is not limited to, dizziness and dyspnea

${ }^{\dagger}$ Extensive limb swelling of an entire proximal and/or distal limb segment with segment defined as extending from one joint to the next (16)

$g$ "Other" includes, but is not limited to, vaccination site pain and vaccination site swelling $\mathrm{h}$ "Other" includes, but is not limited to, lymphadenopathy and arthralgia

Figure 3: Distribution of primary adverse events following immunization reported by age group, $2017^{\mathrm{a}}$

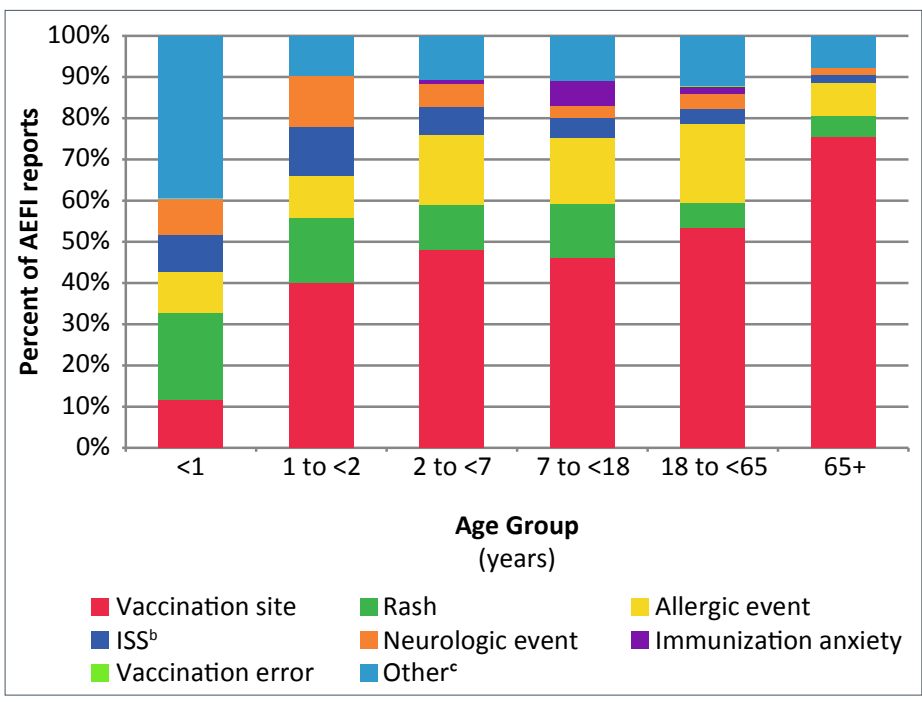

Abbreviations: AEFI, adverse events following immunization; ISS, infection/syndrome/systemic symptoms; $<$, less than; + , and above

Eighteen reports with missing age and three reports with missing primary AEFI are excluded b The ISS are primarily events involving many body systems often accompanied by fever. They include sub-categories such as recognized syndromes (e.g. Kawasaki syndrome, fibromyalgia, etc.), fever alone, influenza-like illness and systemic events (such as fatigue, malaise and lethargy). They also include evidence for infection in one or more body parts

"Other" includes arthralgia, arthritis, hypotonic-hyporesponsive episode, intussusception, gastrointestinal diseases, anaesthesia/paraesthesia, parotitis, persistent crying, thrombocytopenia sudden infant death syndrome and sudden unexpected/unexplained death syndrome

children under one year of age, the most commonly reported AEFI was rash alone, followed by vaccination site reactions (Figure 3). 


\section{Health care utilization}

Table 2 shows the reported highest level of care sought following an AEFI. The most frequently reported highest level of health care usage was non-urgent health care visit (40\%), followed by emergency visit (24\%). Most people with a reported $\mathrm{AEFI}(93 \%)$ did not require hospitalization. In $23 \%$ of cases, no health care was sought.

Table 2: Highest level of health care sought for adverse events following immunization, 2017

\begin{tabular}{|c|c|c|}
\hline $\begin{array}{l}\text { Highest level of care sought } \\
\qquad(N=2,709)^{a}\end{array}$ & $\mathbf{n}$ & $\% b^{b}$ \\
\hline Required hospitalization ( $\geq 24 \mathrm{hrs}$ ) & 197 & 7 \\
\hline $\begin{array}{l}\text { Resulted in prolongation of existing } \\
\text { hospitalization }\end{array}$ & 1 & $<0.1$ \\
\hline Emergency visit & 639 & 24 \\
\hline Non-urgent visit & 1,088 & 40 \\
\hline $\begin{array}{l}\text { Telephone advice from a health } \\
\text { professional }\end{array}$ & 127 & 5 \\
\hline None & 623 & 23 \\
\hline Unknown & 34 & 1 \\
\hline
\end{tabular}

\section{Outcome}

The outcome at time of reporting for all AEFI reports is shown in Table 3. Full recovery was reported in $75 \%$ of the reports and less than $0.1 \%$ of reports reported death as an outcome. For those not fully recovered at the time of reporting, the reports are revised if updated information is received by CAEFISS from the provinces and territories.

Table 3: Outcome at time of reporting for all adverse events following immunization reports, 2017

\begin{tabular}{|l|r|r|}
\multicolumn{1}{|c|}{\begin{tabular}{c}
\multicolumn{1}{c|}{$\begin{array}{c}\text { Outcome } \\
(\mathrm{N}=2,878)^{\mathrm{a}}\end{array}$} \\
Fully recovered
\end{tabular}} & \multicolumn{2}{|c|}{$\%^{\mathrm{b}}$} \\
\hline $\begin{array}{l}\text { Not yet recovered at time of } \\
\text { reporting }\end{array}$ & 589 & 75 \\
\hline Permanent disability / incapacity & 1 & 20 \\
\hline Death & 4 & $<0.1$ \\
\hline Unknown & 130 & 0.1 \\
\hline
\end{tabular}

Abbreviations: $\mathrm{n}$, number; $\mathrm{N}$, total number; $<$, inferior to

Eighty-two cases were missing information on outcome, therefore were excluded

Percentages in table do not total $100 \%$ due to rounding

\section{Serious adverse event reports}

Overall there were 253 SAE reports out of over 23 million vaccine doses distributed during the reporting period. This represents a reporting rate of 1.1/100,000 doses distributed and
$9 \%$ of all AEFI reports for the 2017 time period. Figure 4 shows the distribution of SAE reports by reason for seriousness, with hospitalization $(n=192)$ and life threatening events $(n=49)$ being the most common reasons.

\section{Figure 4: Classification of serious adverse events} reports, $2017^{\text {a }}$

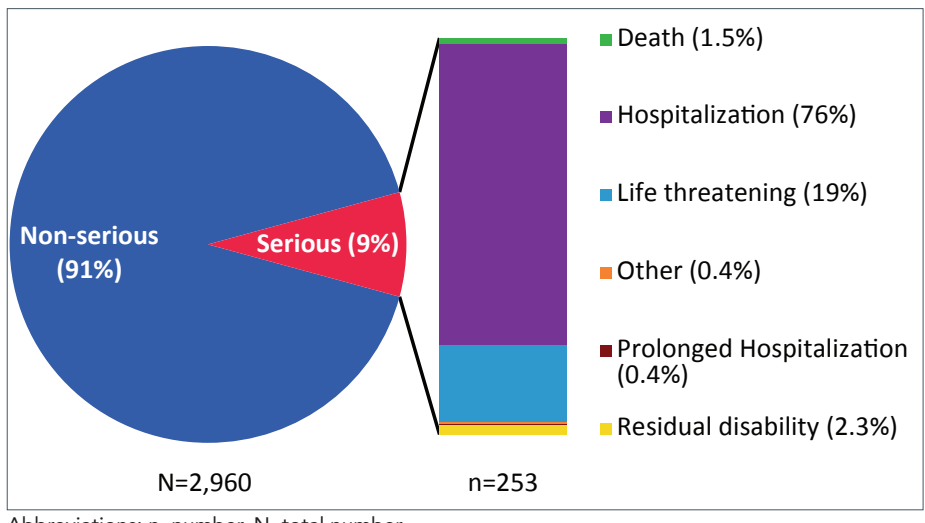

Abbreviations: $\mathrm{n}$, number, $\mathrm{N}$, total number

a Percentages in figure do not total $100 \%$ due to rounding

Among the SAE reports, the most frequently reported primary AEFI was seizure $(n=58,23 \%)$, followed by anaphylaxis $(n=33$, $13 \%)$. The majority $(n=183,72 \%)$ of SAE reports had fully recovered at the time of reporting. For those patients who had not fully recovered at the time of reporting, these reports were revised if updated information was received by CAEFISS from the provinces and territories. Other outcomes for SAE reports included fatal outcome $(n=4,2 \%)$, permanent disability/ incapacity $(n=1,0.4 \%)$, unknown outcome $(n=15,6 \%)$ and missing information on outcome $(n=5,2 \%)$.

The majority of SAEs were in children and adolescents less than 18 years of age $(81 \%)$, with almost three quarters $(74 \%)$ of these SAEs being reported in children under the age of two years.

There were two deaths in those less than two years of age and two deaths in those 18 years of age and older. After careful review, all deaths were considered to be a result of pre-existing conditions (heart surgery, serious injury, cardiovascular disease, diabetes and hypertension) and not to the vaccines administered. There was also one reported outcome of disability that occurred in an individual. The medical history was reviewed for this individual and it was concluded, based on the information provided, that the disability was not considered to be related to the administered vaccine.

\section{Discussion}

In 2017, the overall annual AEFI reporting rate was $12.6 / 100,000$ doses distributed or $8.1 / 100,000$ population, with a statistically significant downward trend in reporting rates over the last 11 years. There are several possible explanations for the declining overall rate of $A E F I$ reporting. It may be due to under-reporting, 
variations in the reporting of expected milder events, or differences in vaccine uptake.

The majority of reports (91\%) was due to non-serious events and differed with age, with rash being more common in infants and vaccination site reactions more common in the elderly. Male predominance was observed for children under seven years of age and female predominance was observed among those seven years and older. The results of a greater proportion of reports involving females is similar to other findings where females in the adult population were found to consistently report more adverse events $(3,4,17)$. The reported sex differences by age may also be explained in part by higher vaccine coverage in female adults (18). The majority of SAEs occurred in children and adolescents, which may in part be explained by IMPACT, which actively searches for specific surveillance targets in children admitted to 12 pediatric tertiary care hospitals $(9,19)$. The greater proportion of SAEs seen in children under two years of age is likely due in large part to the number of vaccines provided to this age group to protect them when they are most vulnerable to vaccine-preventable diseases. Although the percentage of SAEs increased from 8\% (between 2013 and 2016) to $9 \%$ (in 2017), this increase may be due to a decrease in the reporting of non-serious AEFls. The 2017 SAE reporting rate was consistent with previously reported rates and there were no unexpected vaccine safety issues identified (4).

\section{Limitations}

Passive surveillance for AEFls is subject to limitations such as underreporting, over reporting, lack of certainty regarding the diagnostic validity of a reported event, missing information regarding other potential causes such as underlying medical conditions or concomitant medications and the differing AEFI reporting practices by jurisdictions within Canada.

There are also limitations associated with active surveillance. The IMPACT uses predetermined AEFI targets (such as seizure), which may limit its ability to identify new adverse reactions to immunizations. In addition, IMPACT focuses on admitted pediatric cases, which means that only the most serious cases are detected. Lastly, IMPACT is not comprehensive, as it covers only $90 \%$ of Canada's tertiary care pediatric beds and hospital admissions $(19,20)$. Despite these limitations, IMPACT is able to fulfill an important role in vaccine safety surveillance by actively identifying targeted serious AEFls in the pediatric population.

In addition, the number of doses administered in the population is not available at the national level; therefore, the denominator used in rate calculations is estimated either from doses distributed or from population statistics. The use of doses distributed is the best available denominator. However, it does have certain limitations:
- It does not equal the number of doses administered

- It does not take wastage into account

- It may not be complete at time of publication, due to reporting delays by the Market Authorization Holders

A population-based denominator was used for demographic analysis (sex-specific and age-specific rates) for this report. A limitation of using a population-based denominator is that it assumes similar distribution of vaccine doses across population subgroups and geographic areas, even though this may not be true in all cases.

\section{Conclusion}

Canada's continuous monitoring of the safety of marketed vaccines in 2017 did not identify any increase in the frequency or severity of AEFls, or identify previously unknown AEFls. The majority of reported AEFls were both expected and mild in nature. Vaccines marketed in Canada continue to have an excellent safety profile.

\section{Authors' statement}

KJ — Formal analysis, validation, writing-original draft, writing-review and editing

CC - Software, formal analysis, validation, writing-original draft, writing-review and editing

HA - Validation, writing-review and editing, supervision

\section{Conflict of interest}

None.

\section{Acknowledgments}

This report would not be possible without the contribution of the public, public health professionals, IMPACT investigators, nurse monitors, the Canadian Paediatric Society and local/regional and provincial/territorial public health authorities that submitted reports to CAEFISS, as well as the ongoing collaboration of the members of the Vaccine Vigilance Working Group. Furthermore, we would like to thank the members of the Vaccine Vigilance Working Group for input and support in the development of this report.

Finally, we would like to thank each individual who took the time to submit an AEFI report for their contribution to vaccine safety in Canada.

\section{Funding}

This work was funded by the Public Health Agency of Canada.

\section{References}

1. Public Health Agency of Canada. Canadian Adverse Event Following Immunization Surveillance System (CAEFISS). Ottawa (ON):PHAC; 2016. https://www.canada.ca/en/public- 
health/services/immunization/canadian-adverse-eventsfollowing-immunization-surveillance-system-caefiss.html

2. Public Health Agency of Canada. Canadian Immunization Guide: Part 2-Vaccine Safety. Ottawa (ON): PHAC; [updated 2013 Jun]. www.canada.ca/ en/public-health/services/publications/healthy-living/ canadian-immunization-guide-part-2-vaccine-safety/page2-vaccine-safety.html

3. Law BJ, Laflèche J, Ahmadipour N, Anyoti H. Canadian Adverse Events Following Immunization Surveillance System (CAEFISS): Annual report for vaccines administered in 2012. Can Commun Dis Rep 2014 Dec;40 Suppl 3:7-23. DOI PubMed

4. Ahmadipour N, Watkins K, Fréchette M, Coulby C, Anyoti H, Johnson K. Vaccine safety surveillance in Canada: reports to CAEFISS, 2013-2016. Can Commun Dis Rep 2018;44(9):20614. DOI

5. Council for International Organizations of Medical Sciences (CIOMS) and World Health Organization. (WHO). Definition and Application of Terms for Vaccine Pharmacovigilance. Report of ClOMS/WHO Working Group on Vaccine Pharmacovigilance. Geneva, Switzerland: CIOMS and WHO; 2012. http://www.who.int/vaccine_safety/initiative/tools/ ClOMS_report_WG_vaccine.pdf

6. International Conference on Harmonisation (ICH) of Technical Requirements for Registration of Pharmaceuticals for Human Use. ICH Harmonised Tripartite Guideline. Clinical Safety Data Management: Definitions and Standards for Expedited reporting E2A. Current Step 4 version. ICH: Oct 27, 1994. www.ich.org/fileadmin/Public_Web_Site/ICH_Products/ Guidelines/Efficacy/E2A/Step4/E2A_Guideline.pdf

7. Public Health Agency of Canada. Adverse events following immunization reporting form. Ottawa (ON): PHAC; 2016 Sep. https://www.canada.ca/content/dam/phac-aspc/ documents/services/immunization/adverse-event s-following-immunization-reporting-declaration-manif estations-cliniques-inhabituelles-suite-immunisation-eng.pdf

8. Morris R, Halperin SA, Déry P, Mills E, Lebel M, MacDonald N, Gold R, Law BJ, Jadavji T, Scheifele D, Marchessault V, Duclos P. IMPACT monitoring network: A better mousetrap. Can J Infect Dis 1993 Jul;4(4):194-5. DOI PubMed

9. Scheifele DW, Halperin SA; CPS/Health Canada, Immunization Monitoring Program, Active (IMPACT). Immunization Monitoring Program, Active: a model of active surveillance of vaccine safety. Semin Pediatr Infect Dis 2003 Jul;14(3):213-9. DOI PubMed

10. International Conference on Harmonisation (ICH). Support Documentation. Medical Dictionary for Regulatory Activities. www.meddra.org/how-to-use/support-documentation/ english
11. Vaccine Vigilance Working Group and the Public Health Agency of Canada. Reporting Adverse Events Following Immunization (AEFI) in Canada: User guide to completion and submission of AEFI reports. Ottawa (ON): PHAC; 2011 Aug. www.canada.ca/en/public-health/services/ immunization/reporting-adverse-events-followingimmunization/user-guide-completion-submissio n-aefi-reports.html

12. Statistics Canada. Population estimates on July $1 \mathrm{st}$, by age group and sex (Table 17-10-0005-01). CANSIM (database). www150.statcan.gc.ca/t1/tb/1/en/tv.action?pid=1710000501

13. SAS Enterprise Guide version 5.1. Cary, NC, USA: SAS Institute Inc., Copyright 2012. All Rights Reserved.

14. van der Maas NA, Bondt PE, de Melker H, Kemmeren JM. Acute cerebellar ataxia in the Netherlands: a study on the association with vaccinations and varicella zoster infection. Vaccine 2009 Mar;27(13):1970-3. DOI PubMed

15. Sejvar JJ, Kohl KS, Bilynsky R, Blumberg D, Cvetkovich T, Galama J, Gidudu J, Katikaneni L, Khuri-Bulos N, Oleske J, Tapiainen T, Wiznitzer M; Brighton Collaboration Encephalitis Working Group. Encephalitis, myelitis, and acute disseminated encephalomyelitis (ADEM): case definitions and guidelines for collection, analysis, and presentation of immunization safety data. Vaccine 2007 Aug;25(31):5771-92. DOI PubMed

16. Woo EJ, Burwen DR, Gatumu SN, Ball R; Vaccine Adverse Event Reporting System Working Group. Extensive limb swelling after immunization: reports to the Vaccine Adverse Event Reporting System. Clin Infect Dis 2003 Aug;37(3):3518. DOI PubMed

17. Harris T, Nair J, Fediurek J, Deeks SL. Assessment of sex-specific differences in adverse events following immunization reporting in Ontario, 2012-15. Vaccine 2017 May;35(19):2600-4. DOl PubMed

18. Public Health Agency of Canada. Vaccine uptake in Canadian adults: Results from the 2016 adult National Immunization Coverage Survey (aNICS). 2018. https://www.canada. ca/en/services/health/publications/healthy-living/201 6-vaccine-uptake-canadian-adults-survey.html

19. Bettinger JA, Halperin SA, Vaudry W, Law BJ, Scheifele DW Canadian IMPACT members. The Canadian Immunization Monitoring Program, ACTive (IMPACT): Active surveillance for vaccine adverse events and vaccine-preventable diseases. Can Commun Dis Rep 2014 Dec;40 Suppl 3:41-4. DOI PubMed

20. Scheifele DW, Halperin SA; CPS/Health Canada, Immunization Monitoring Program, Active (IMPACT). Immunization Monitoring Program, Active: A model of active surveillance of vaccine safety. Semin Pediatr Infect Dis 2003 Jul;14(3):213-9. PubMed https://doi.org/10.1016/S10451870(03)00036-0

\section{Appendix 1: Supplementary figures (available upon request)}

Figure A1: Proportion of adverse events following immunization reports by active versus passive surveillance in children less than 18 years of age, 2017

Figure A2: Annual reporting rate of adverse event following immunization reports by age group, 2007-2017 